\title{
Effects of static bottlenecks on traffic flow in urban road network
}

\author{
John N. P. Mahona ${ }^{1,2}$, Cuthbert F. Mhilu², Joseph Kihedu ${ }^{2}$, Hannibal Bwire ${ }^{3}$ \\ ${ }^{1 *}$ Department of Transport Engineering and Technology, National Institute of Transport, Dar es Salaam, TANZANIA \\ ${ }^{2}$ Department of Mechanical and Industrial Engineering, University of Dar Es Salaam, TANZANIA \\ ${ }^{3}$ Department of Transportation and Geotechnical Engineering, University of Dar Es Salaam, TANZANIA \\ "Corresponding Author: e-mail: johnmahona48@gmail.com, Tel + +255-754577474 \\ ORCID iD: https://orcid.org/0000-0002-4652-9183 (Mahona), https://orcid.org/0000-0002-7515-1888 (Mhilu), https://orcid.org/0000-0002-7371-2688 (Kihedu), \\ https://orcid.org/0000-0002-4595-2502 (Bwire)
}

\begin{abstract}
Existing traffic flow models do not consider the effects of road static bottlenecks on traffic flow. In this paper, a modified macroscopic continuum model for traffic flow on urban road network with static bottlenecks is presented. The model takes into account the fluctuations of traffic flow considering static bottlenecks during the morning peak period. The model results show that existence of static road bottlenecks with various configurations cause traffic flow instabilities. This phenomenon lead into stop-and-go traffic flow conditions under the moderate density and reduction of the traffic system's efficiency. Furthermore, results show that an increase in traffic density is accompanied by a significant decrease of speed which adversely influences performance of roadway and decrease the traffic system's efficiency and thus resulting to the occurrence of congestions. The methodological aspects of the study and results will enable traffic engineers and planners to assess and improve existing urban road networks.
\end{abstract}

Keywords: Traffic flow, Bottlenecks, stability, Stop-and-go traffic, System's efficiency, Congestion.

DOI: http://dx.doi.org/10.4314/ijest.v12i3.1

Cite this article as:

Mahona J.N., Mhilu C.F., Kihedu J., Bwire H. 2020. Effects of static bottlenecks on traffic flow in urban road network. International Journal of Engineering, Science and Technology, Vol. 12, No. 3, pp. 1-15. doi: 10.4314/ijest.v12i3.1

Received: September 9, 2019; Accepted: November 30, 2019; Final acceptance in revised form: April 24, 2020

\section{Introduction}

Traffic congestion remains a significant problem facing various countries worldwide, resulting into various social economic and environmental problems, such as, lost opportunities, massive delays and pollution. The problem has attracted a number of researchers who have attempted to formulate traffic flow models to study the complex traffic phenomena from different perspectives (Boel and Mihaylova, 2006; Jiang et al., 2007; Lattanzio et al., 2011; Tang et al., 2013; Hawes et al., 2016). These models are responsible for evaluating the roadway system performance by considering the macroscopic traffic flow behaviors (flow, density and speed) of the road segment (Jin et al., 2014; Strnad et al., 2016). They give the general behaviour of macroscopic flow pattern fluctuations along the specific roadway, thus illustrating for either free or congested flow.

The traffic flow models can be divided into macro and micro models and among these traffic flow models, macro models are simple and therefore they have been used to analyze shock wave, rarefaction wave and small perturbation (Leclercq et al., 2014; Tang et al., 2009; Gupta and Sharma, 2010; Tie-Qiao et al., 2012; Gupta and Sharma, 2012; Tang et al., 2013). Although these traffic flow models can describe many complex traffic phenomena, they are not used to study the effects of static road bottlenecks on traffic flow as this factor is not taken into account. In order to study the traffic phenomena resulted from the fluctuations of 
traffic flow variations due to the existence of static bottlenecks (e.g., bus station, humps, vehicle breakdown, merging/unmerging, etc.) the models have to take into consideration the Traffic Friction Effects (TFE) caused by the static bottlenecks on traffic flow on the roads. To study the impact of the bottlenecks on the speed of the main traffic flow and the resulting variations in vehicle flow rate and density, the TFE has to be introduced into the momentum equation (Liu et al., 1996; Gupta, 2013; Ajitha et al., 2015). In this paper, a modified macro continuum traffic flow model with consideration of static bottlenecks to study the effects of the traffic friction effects on traffic flow during morning inbound travel direction is presented, as it is during this time slot most of the roadway sections do experience regular traffic congestion.

Macroscopic traffic flow variations are in general repeated every day still they vary in the time-of-day. Further, traffic flow may start in a very low level in the early morning and gradually increase up to the peak during morning peak hours, which is always occur from 5:30 am to 10:00 am, and evening peak from 16:00 pm to 21:00 pm (Hou et al., 2008; Mahona et al., 2019). Generally speaking, the occurrence of traffic congestion in urban road network in the macroscopic fashion shows inherent repeatability every day at different time slot. In real traffic operations, road bottlenecks such as bus stations, humps, vehicle breakdown, merging/unmerging traffic, and $T$ - junctions and cross junctions widely exist on the roadway leading to occurrence of complex traffic flow behavior (e.g. stop-and-go and queues). This study proposes a modified continuum model which can be used to analyze effects of the existence of static bottlenecks that can impacts traffic flow on urban road network. The study demonstrates the applicability of the proposed model to examine influences of traffic friction effects resulted by the existence of static bottlenecks under various traffic conditions in Dar es Salaam city.

\section{Models of Traffic Flow}

The early macroscopic model was formulated by Lighthill and Whitham (1955) and Richards (1956) named as the LWR model, where mean vehicle speed assumed to be in steady state condition under all circumstances. The control equations were illustrated as follows (Mohan and Ramadurai, 2013):

$$
\begin{aligned}
& \left\{\begin{array}{l}
\rho_{t}+q_{x}=0 \\
q=\rho u_{e}(\rho)
\end{array}\right. \\
& u_{e}(\rho)=u_{f}\left(1-\frac{\rho_{i n}}{\rho_{i j}}\right)
\end{aligned}
$$

where $\rho_{t}$ is the density at time $t, q_{x}$ is the flow at the specified location $x$ and $u_{e}(\rho)$ is the linear equilibrium speed relationship in the time-space $(t-x)$ domain. Equation 1 and 2 fulfill the following conditions:

(1) The equilibrium speed is a decreasing function of the density;

(2) The equilibrium speed, $u_{e}\left(\rho_{i}\right)$, is assumed to be zero when no vehicle on road and when $\rho_{j}$ is the jam density

Equation (1) can be used show the formation and generation of shockwave (Travel disturbance) that has a potential influence upon the traffic flow, but it cannot be applied to study non-equilibrium traffic flow because the speed is not allowed deviate from the equilibrium speed. The speed deviations are mainly due to variations of road geometry like humps, existence of various forms of junctions ( $T$ junctions and Cross junctions) etc. which greatly affect the traffic flow characteristics. To overcome the drawback, researchers later proposed few high-order models which can be categorized into density-gradient (DG) and speed-gradient (SG) models based on variations and dependences of vehicle densities and mean speed (Payne, 1971; Gupta and Katiyar, 2005, 2006; 2007).The early DG model was formulated by Payne (1971) that can be written as follows:

$$
\begin{aligned}
& \left\{\begin{array}{l}
\rho_{t}+(\rho u)_{x}=0 \\
u_{t}+u u_{x}=\frac{u_{e}-u}{\tau}-\frac{u}{\rho T} \rho_{x}
\end{array}\right. \\
& U=u_{e}^{\prime}(\rho)
\end{aligned}
$$

where, $\tau$ is the reaction time (second), $U$ is the anticipation coefficient. The Payne model is able to describe the non-equilibrium property of traffic flow, but its major deficiency is to produce backwards movement under some specific conditions (Daganzo, 1995; Park and Oh, 2015). To overcome the Payne model deficiency, Jiang et al., (2002) proposed the SG models represented as follows: 


$$
\left\{\begin{array}{l}
\rho_{t}+(\rho u)_{x}=0 \\
u_{t}+u u_{x}=\frac{u-u_{e}}{\tau}+c_{0} u_{x}
\end{array}\right.
$$

where $c_{0}$ is the propagation speed of small perturbation and $u_{e}(\rho)$ the non-linear density relationship adopted from Del Castillo and Benitez, (1995) which is formulated as:

$$
u_{e}\left(\rho_{i}^{k}\right)=u_{f}\left(1-\exp \left(1-\exp \left(\frac{c_{0}}{u_{f}}\left(\frac{\rho_{j}}{\rho_{i}^{k}}\right)\right)\right)\right.
$$

Together with the flow conservation and fundamental traffic flow equations, these models illustrate the dynamics of velocity using the relaxation and anticipation terms from Newtonian physics (Mohan \& Ramadurai, 2013). However, Jiang et al., (2002) and its extensions can overcome the deficiency's of Equations (1), (2) and (3) as can be used to study some complex traffic phenomena (e.g. local cluster, stop-and-go, etc.). Again, it cannot be used to study the influences of static bottlenecks on traffic flow behaviour since it does not take due consideration of this factor. Under normal traffic flow operations, any road network has its own specific road geometry acting as the flow bottlenecks that may in influence the traffic flow. This paper proposed the modified continuum macroscopic model to study the impacts of static bottlenecks on traffic flow making use of Jiang et al., (2002) as a base model. The proposed modified model in conservation and momentum form is expressed as follows:

$$
\left\{\begin{array}{l}
\rho_{t}+(\rho u)_{x}=0 \\
u_{t}+u u_{x}=\frac{u-u_{e}}{\tau}+c_{0} u_{x}+F
\end{array}\right.
$$

where $F$ is the Traffic Friction Effect (TFE) resulted by the queue formed due to the existence of road bottlenecks at the prescribed location and time. Based on Equation (5), it is found that the static bottlenecks will produce Traffic Friction Effect (TFE) which will reduce the speed of the main line traffic flow (Figure 1) and these will cause the increase of vehicle density on approaching the bottleneck location thus influencing vehicle flow. These influences are observed by reduction of vehicle speed on approaching the location of static bottlenecks and these cause the increase of vehicle density as well as decreasing the vehicle flow.

The model presented in this paper considers the small disturbances coming from the existence of the static bottlenecks should become high due to its effects. At this point, when the effects due to the existence of static bottlenecks become maximum, change in the speed of the main flow can be noticed. On the other hand, TFE can be observed as a result of speed changes performed due to the reaction of through-going traffic/vehicles attempting to avoid or to provide space for the entering / leaving traffic. From these arguments, the speed of the main line flow should generally decrease on approaching the bottleneck position (Figure 1) resulting into increase of vehicle density thus affecting vehicle flow $(q)$.

The Traffic Friction Effect (TFE) resulted by the static bottlenecks on urban road network may be complex and related to many factors (e.g., the density and flow rate on the static bottlenecks, driving behaviour and the bottleneck geometry), so it is expressed as follows (Mahona, 2020):

$$
\mathrm{F}=\left\{\begin{array}{c}
-\beta \Delta t \rho_{i n} u_{i n}\left(1-\frac{\rho_{\text {in }}}{\rho_{\text {jam }}}\right) \\
\text { else } \\
0
\end{array}\right.
$$

where $\beta$, impedance coefficient, signifies the disturbances to the vehicle flow due to the existence of the bottleneck, $\rho_{\text {in }}$ is initial density, $u_{f}$ is the free flow vehicle speed, $\rho_{\text {jam }}$ critical density at the road section, $\Delta t$ is the change in time. The minus sign in the Equation (8) denotes that the speed of the main line flow decreases due to the impacts of the static bottlenecks at the particular space and time. Equation (8) elaborate that the traffic friction will be maximum when the density on the main line of urban road section approaches maximum flow density and goes to zero when the density approaches zero or jam density. 


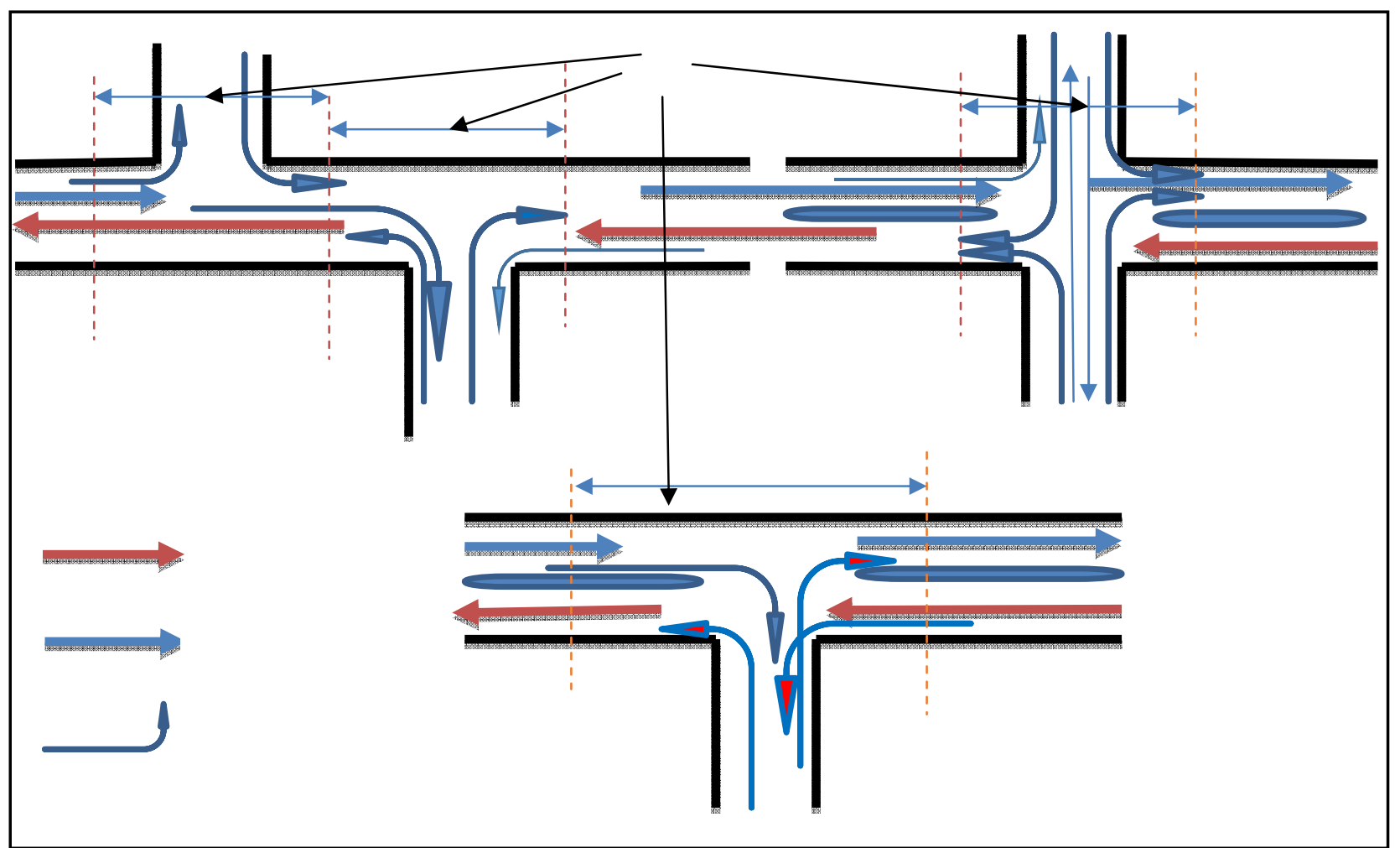

Figure. 1. Schematic diagram of the traffic flow on urban road network with static bottleneck of various Configurations (Mahona, 2020)

Figure 1 illustrates how various forms of static bottlenecks can influence in many ways the traffic flow characteristics (flow, density and speed) on urban road network under real traffic operations. Under normal traffic operation the volume of the merging flow entering the main line freeway depends on the density on the merging area. It is clear that when the density on the merging area is the jam densities, vehicle speed and flow is close to zero, hence no vehicle can enter the main freeway. Similarly, the volume of the diverging flow exiting from the main line freeway depends on the density of the area after the bottlenecks. If the area after the bottlenecks is blocked no vehicle can exit from the main line urban road network. In this instance vehicles may stay on the urban road network section (occupy a lane) or not go to the next exit. Therefore, it is important to pay extra attention to these dynamic features of the merging and diverging flows while modelling traffic flow on urban road network with various road geometries. These assertions are elaborated by Equation (8) as follows:

i. If $\rho_{i n}$ is close to $\rho_{\text {jam }}$ then the TFE is close to zero thus no TFE induced by the existence of the static bottlenecks

ii. If $\rho_{\text {in }}$ is very high compared to $\rho_{\text {jam }}$ it indicates that the existence of static bottlenecks may cause reduction of vehicle speed and hence high impacts. Whereas if $\rho_{i n}$ is very small compared to $\rho_{\text {jam }}$, indicates high vehicle speed

iii. If $\rho_{i n}$ is relatively close to $\rho_{\text {jam }}$ then the vehicle flow is high to affect the vehicle speed and at that point the static bottlenecks have significant impact on vehicle flow.

Note: Above assertions are qualitatively consistent with those of real traffic situations, but the real impacts of TFE needs to be further tested based on the observed field data.

\section{Test Site and Traffic Data}

In this study, the urban road network considered is the Bagamoyo road (about 30km) direction from Morocco bus stop towards Bagamoyo outskirt of Dar es salaam city. The studied road network includes 14 Critical Traffic Points/ locations and that between each CTPs at least two or three static bottlenecks are considered so that modelling one section may represent the whole road network (Figure 2). 


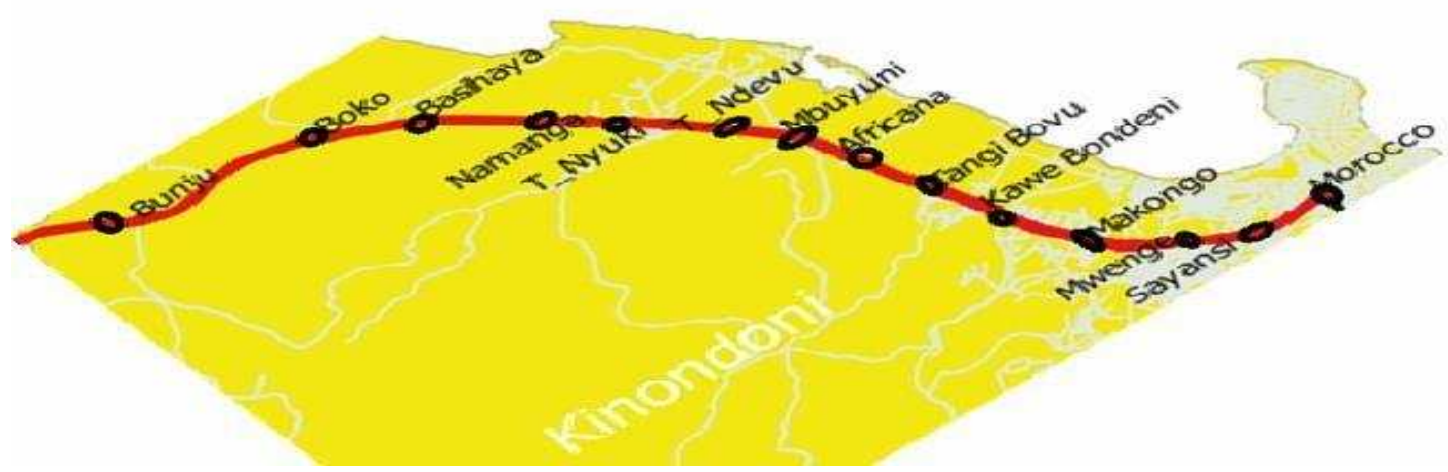

Figure 2. Bagamoyo road network (Morocco bus stop to Bunju towards Bagamoyo Town) (Mahona, 2020).

Figure 3 represents the examined urban road network in terms of Critical Traffic Points (CTPs) and between each CTPs it indicates a bifurcation point or a junction or any location illustrating a change of the network structure. From the Figure 3 , the static bottlenecks which show the significant change of traffic flow are located at or near CTPs on the road network. The section on the road network where traffic flow parameters are made are subdivided in model sections of equal length marked by a bullet. Using this representation, the network sections are well-defined and the model equations presented in Section 4 and are directly applied to these sections. Furthermore, Figure 3 indicates the number of lanes, the length in meters between each CTPs as well as the bottleneck configurations as well as their locations.

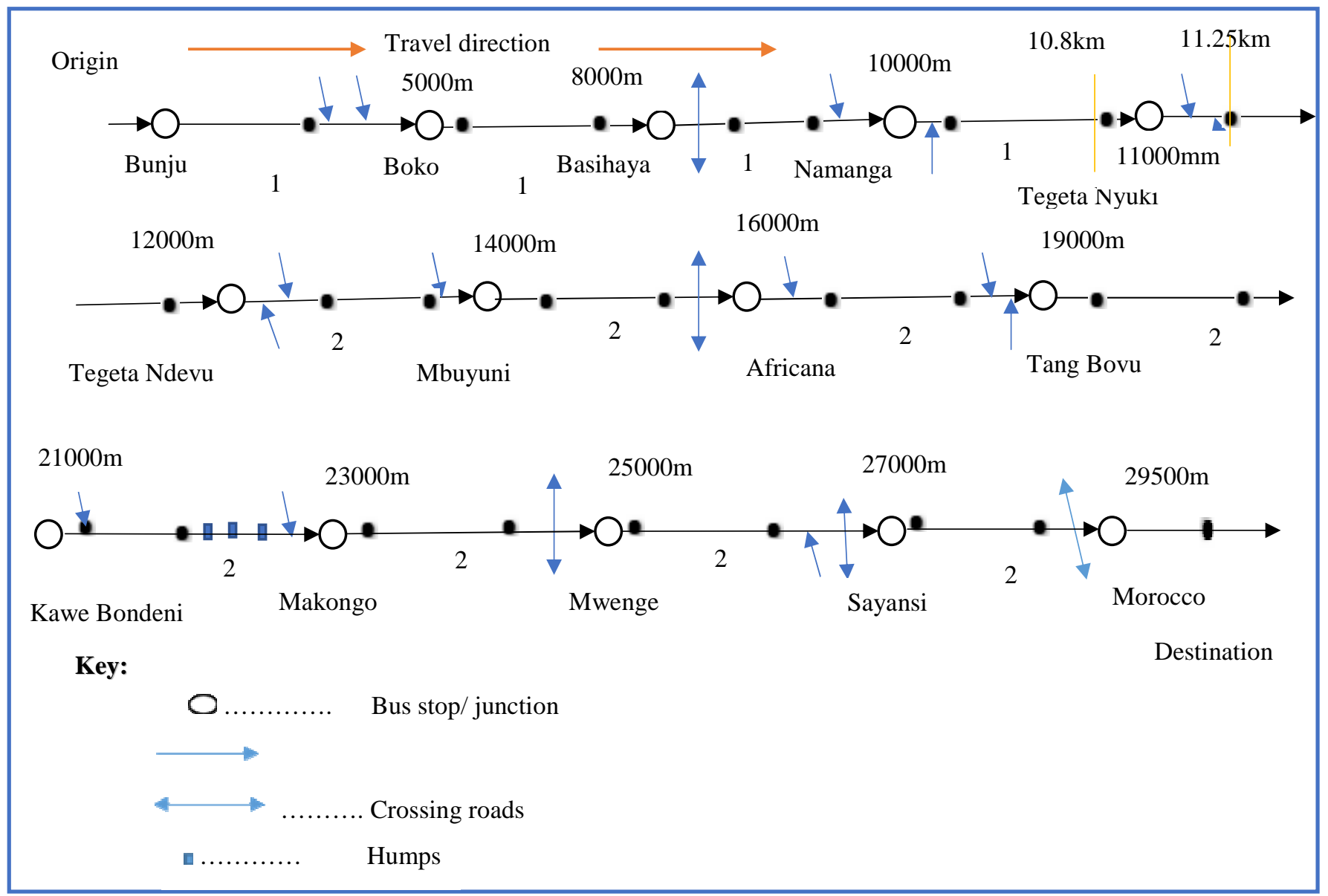

Figure 3. Representation of Bagamoyo urban road (Mahona, 2020)

In this study, data are manually collected using the tally sheets, note pads and stop watch which has the advantage of being flexible to complying with the existing conditions as one can decide at any time where to locate the place for data collection 
without consuming more time for preparations. This enables the collection of initial vehicle flow and density at each road stretch with the time resolution of 15 minutes for the periods of June - November 2018. These data are represented in five days of the week (Monday - Friday). The data pre-analysis showed that, within this particular road network occurrence of recurrent traffic congestion is observed during the morning peak hours $5.30 \mathrm{pm}-10.00$ am inbound (towards the CBD) at all CTPs.

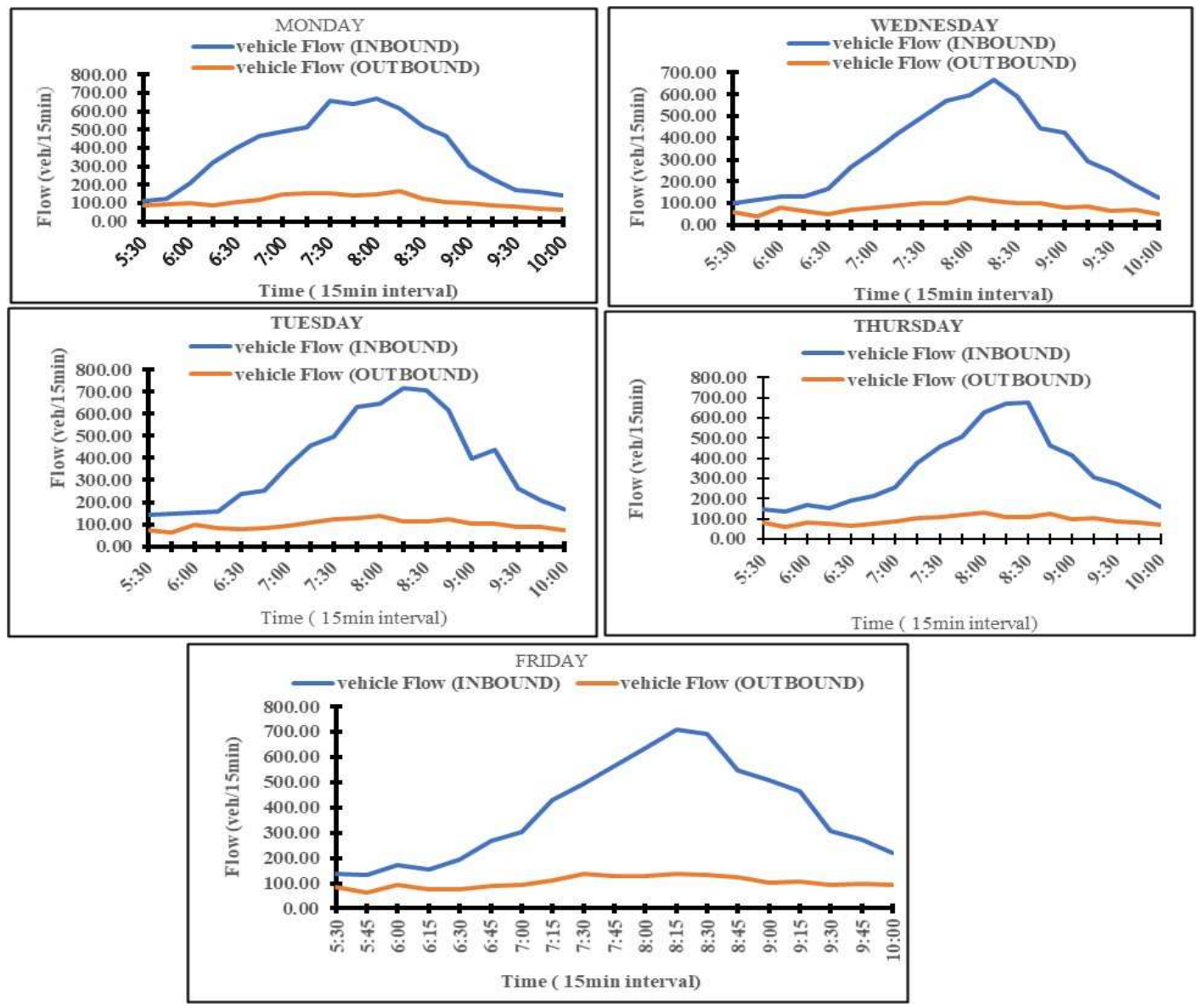

Figure 4. Observed flow data of the Bagamoyo road at Tegeta-Nyuki area during morning peak period for six months period presented in one week (Monday to Friday)

The Figure 4 presents the observed vehicle flow ( $q$ veh/15min) data at Tegeta-Nyuki on Bagamoyo road network in Dar Es Salaam Tanzania during the morning peak period of one week (representing six-month data spanning from May to November 2018 reduced to one-week days i.e. Monday - Friday). The figure shows that the outbound flow direction is stable and low during the morning peak period, while the inbound flow first increases to the predetermined value and then decreases. Observing Figure 4, we can deduce that the expected average input traffic flow $\left(q_{i n} \mathrm{veh} / 15 \mathrm{~min}\right)$ of the static bottleneck and the expected maximum /critical traffic average flow ( $\left.\mathrm{q}_{\text {out }} \mathrm{veh} / 15 \mathrm{~min}\right)$ (at the bottleneck) are as follows:

$$
q_{i n}=120 \text { Vehicle } / 15 \text { minutes, } q_{\text {out }}=700 \text { vehicle } / 15 \text { minutes }
$$

From Figure 2, it is observed that beyond the average maximum /critical traffic flow ( $q_{\text {out }}$ veh/15min) (at the bottleneck) the road stretch will be at a jam condition. Again, based on Figure 4, it is observed that time of the actual morning peak period lasts only about one hour and half, so the study of the effects of static bottleneck has on the main road during the actual morning peak period can be conducted successfully.

The Figure 5 presents the observed vehicle flow ( $q$ veh/15min) - Density $(\rho \mathrm{veh} / \mathrm{km})$ data at Tegeta-Nyuki on Bagamoyo road network in Dar Es Salaam Tanzania during the morning inbound rush period of one weekday (representing the six-month data spanning from May to November 2018 reduced to one-week days i.e. Monday - Friday). The figures shows only inbound as it is the time when traffic congestions are mostly noticed compared to outbound flow direction. On observing Figure 5 the vehicle density first increases with the vehicle flow to a cutoff point where it then decreases to a minimum point. Observing Figure 5, we can deduce that the expected average maximum /critical vehicle density $\left(\rho_{j a m} \mathrm{veh} / \mathrm{km}\right)$ (at the bottleneck) is close to 200 
Vehicle/km. From data collected, the vehicle mean speed is estimated by employing the fundamental traffic flow relation expressed as follows:

$$
q_{i}^{k}=\rho_{i}^{k} u_{i}^{k}
$$

where flow, $q$ and $\rho$ are empirical data extracted from the Figure 5
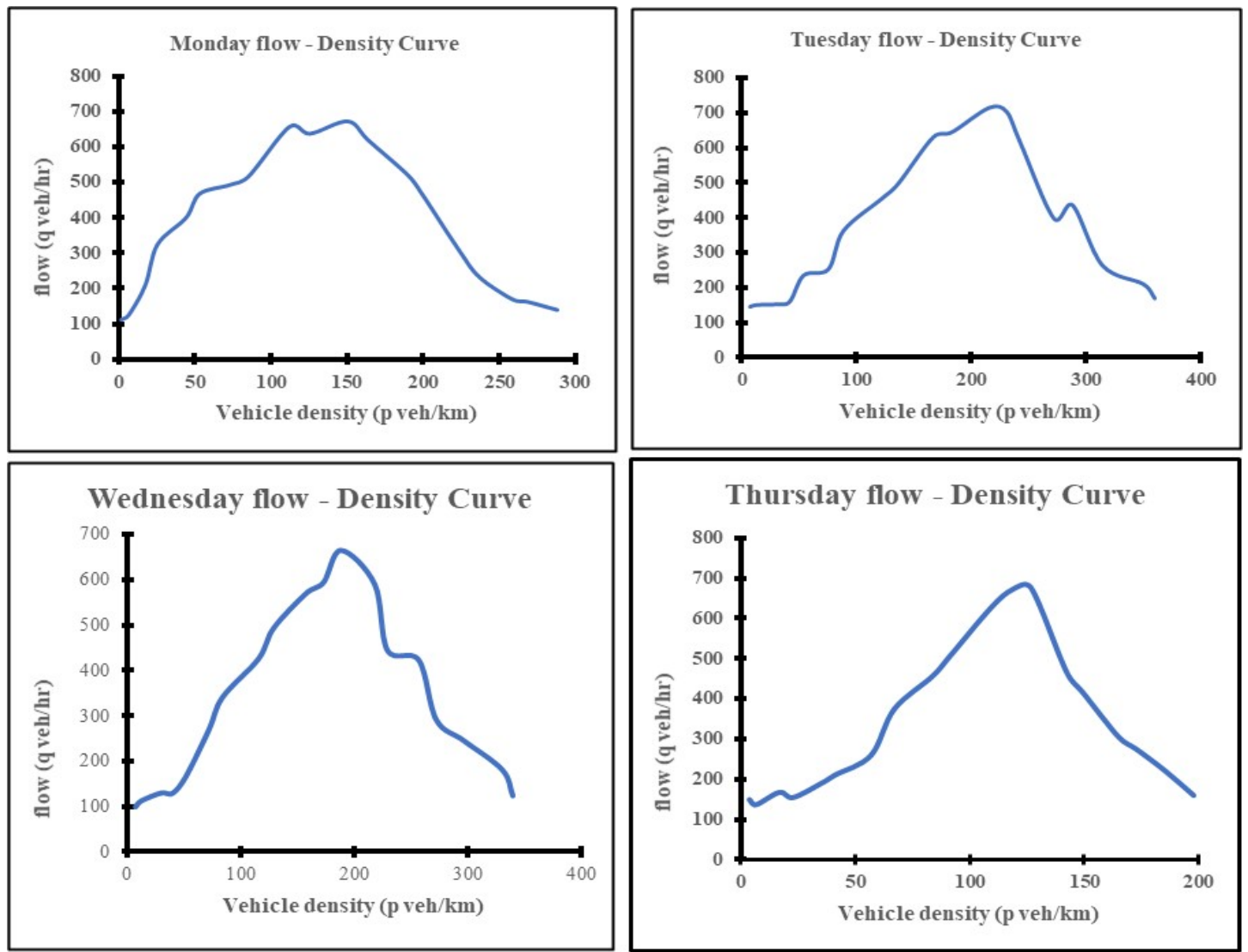

Figure 5. Observed Vehicle flow - density data of the Bagamoyo road at Tegeta-Nyuki area during the morning peak period for six months period presented in week (Monday's to Friday's)

\section{Model Numerical Tests}

From theory point of view, it is not easy to analytically study the complex traffic phenomena produced by existence of various static bottleneck, hence we use simulations to illustrate the effects that static bottlenecks have on urban road network. To get the analytical solution of the model Equation (7), we use numerical scheme to discretize it. Various numerical schemes are considered to discretize this equation, but having no significant impacts on the numerical results, for this reason we opt to use the upwind scheme to discretize Equation. (7) (Jiang et al., 2001; Jiang, et al., 2002; Tang et al., 2007; Jiang et al., 2007):

$$
\begin{aligned}
& \rho_{i}^{k+1}=\rho_{i}^{k}+\frac{\Delta t}{\Delta x} \rho_{i}^{k}\left(u_{i}^{k}-u_{i+1}^{k}\right)+\frac{\Delta t}{\Delta x} u_{i}^{k}\left(\rho_{i-1}^{k}-\rho_{i}^{k}\right) \\
& \rho_{i}^{k+1}=\rho_{i}^{k}+\frac{\Delta t}{\Delta x}\left(\rho_{i-1}^{k} u_{i}^{k}-\rho_{i}^{k} u_{i+1}^{k}\right)
\end{aligned}
$$

Case 1: If traffic is heavy i.e. $u_{i}^{k}<c_{0}$ (Low mean vehicle speed)

$$
u_{i}^{k+1}=u_{i}^{k}+\frac{\Delta t}{\Delta x}\left(c_{0}-u_{i}^{k}\right)\left(u_{i+1}^{k}-u_{i}^{k}\right)+\frac{\Delta t}{\tau}\left(U_{e}\left(\rho_{i}^{k}\right)-u_{i}^{k}\right)+F_{i}
$$

Case 2: If traffic is lower i.e. $u_{i}^{k}>c_{0}$ (High mean vehicle speed) 


$$
\begin{aligned}
& u_{i}^{k+1}=u_{i}^{k}+\frac{\Delta t}{\Delta x}\left(c_{0}-u_{i}^{k}\right)\left(u_{i}^{k}-u_{i+1}^{k}\right)+\frac{\Delta t}{\tau}\left(U_{e}\left(\rho_{i}^{k}\right)-u_{i}^{k}\right)+F_{i} \\
& F_{i}=-\beta \rho_{i}^{k} u_{i}^{k}\left(1-\frac{\rho_{i}^{k}}{\rho_{j a m}}\right)
\end{aligned}
$$

where $i$ and $k$ stands for road section and the time step respectively, $U_{e} \rho_{i}^{k}$ is vehicle equilibrium speed under non-equilibrium given by the Equation (6), $u_{f}$ the free-flow is speed and $\rho_{j a m}$ is jam density.

To study the traffic phenomena that bottlenecks produce on a road network we assume the following boundary conditions apply,

$$
(L, t)=\rho(0, t), u(L, t)=u(0, t),
$$

where $L=30 \mathrm{~km}$ is the length of the Bagamoyo road network, $\mathrm{t}$ is the time interval, $\mathrm{u}$ is the vehicle speed at the given time, $t$ and $\rho$ is the vehicle density at the particular time and location. We use Equation (6) for the vehicle equilibrium speed, as we consider the non-equilibrium condition caused by the existence of static bottlenecks on urban roads.

Furthermore, among many road stretches forming the Bagamoyo road, we use the static bottlenecks located at Tegeta-Nyuki area purposely to study the TFE produced due to the existence of static bottlenecks along the entire network. The bottleneck position is at $x=10.8 \mathrm{~km}$ and the position after the bottleneck is $x=11.25 \mathrm{~km}$ as shown in Figure 3 . The initial density and mean stream speed of each sub-section and other parameters used in the model are presented in Table 1.

Table 1. Initial values and parameters for the modified model

\begin{tabular}{|l|l|l|l|l|l|l|l|l|l|l|l|l|l|l|}
\hline Location & 1 & 2 & 3 & 4 & 5 & 6 & 7 & 8 & 9 & 10 & 11 & 12 & 13 \\
\hline Vehicle speed & 15.40 & 2.42 & 1.40 & 1.24 & 3.50 & 4.00 & 4.00 & 3.00 & 6.00 & 4.00 & 5.00 & 8.00 & 11.00 \\
\hline Vehicle density & 0.002 & 0.031 & 0.072 & 0.082 & 0.128 & 0.165 & 0.150 & 0.140 & 0.020 & 0.021 & 0.001 & 0.050 & 0.114 \\
\hline Parameters & $u_{f}$ & $\rho_{\text {jam }}$ & $\tau$ & $c_{0}$ & $\beta$ & $\Delta x$ & $\Delta \mathrm{t}$ & & & & & \\
& $12.5 \mathrm{~m} / \mathrm{s}$ & $0.2 \mathrm{veh} / \mathrm{m}$ & $10 \mathrm{~s}$ & $2.78 \mathrm{~m} / \mathrm{s}$ & 0.1 & $100 \mathrm{~m}$ & $1 \mathrm{~s}$ & & & & & \\
\hline
\end{tabular}

\section{The Effects of Static Bottleneck}

To observe the effects that the static bottlenecks induce on the main line traffic flow on urban road networks, we observe the variations of vehicle stream speed and density illustrated in Figures 6a, 7a, 8a, 9a and 10a and Figures 6b, 7b, 8b, 9b and 10b respectively. On observing Figures $6 a, 7 a, 8 a, 9 a$ and $10 a$, we can deduce the following facts in connection with vehicle stream speed variations-

i. On observing high initial speed above $10 \mathrm{~m} / \mathrm{s}$, small decrease of main line speed on approaching the static bottleneck position are noticed and hence high instabilities are observed of the main line flow. This implies that at this time the vehicle flow on approaching the bottleneck location will exhibit high instabilities.

ii. When the initial speed is below $10 \mathrm{~m} / \mathrm{s}$, small decrease of mainline speed is noticed and hence signifying less significant of existence of static bottleneck on the main line flow.

Whereas, on observing Figures $6 b, 7 b, 8 b, 9 b$ and 10b, following facts are deduced in connection with density variations on approaching the static bottleneck location:

iii. when observed vehicle mean vehicle speed is higher, this corresponds to low density values and vice versa implying for high density on approaching the static bottlenecks location. In this case mean speed has to be low to react to the increase of density.

iv. When the initial densities increase, the uniform vehicle flow becomes unstable which shows that the existence of static bottlenecks influences the stability of the main line traffic flow. From the figures, stop-and-go phenomena will be observed when the density reaches the value between 0.1 and $0.18 \mathrm{veh} / \mathrm{m}$ and the situation will worsen at density above $0.18 \mathrm{veh} / \mathrm{m}$.

These vehicle flow characteristics always observed in big cities during the morning peak period at several sections of the roads, so the inflow towards the static bottlenecks localities should be managed to improve the main road flow. The reason for the occurrence of these characteristics is that the existence of static bottleneck like $T$-junctions, Cross-joint, bus stop, road hump will always increase the density of the main line and thus significantly influencing the main road speed. But when the initial vehicle density approaches the jam density, a complete jam can be observed. In this instance the static bottleneck has no significant effects 
on the mean vehicle speed thus no vehicle movement is observed. The trend of traffic flow state variations is confirmed by the average line which shows that the variations at all segments is similar but differ only at the time of occurrence.

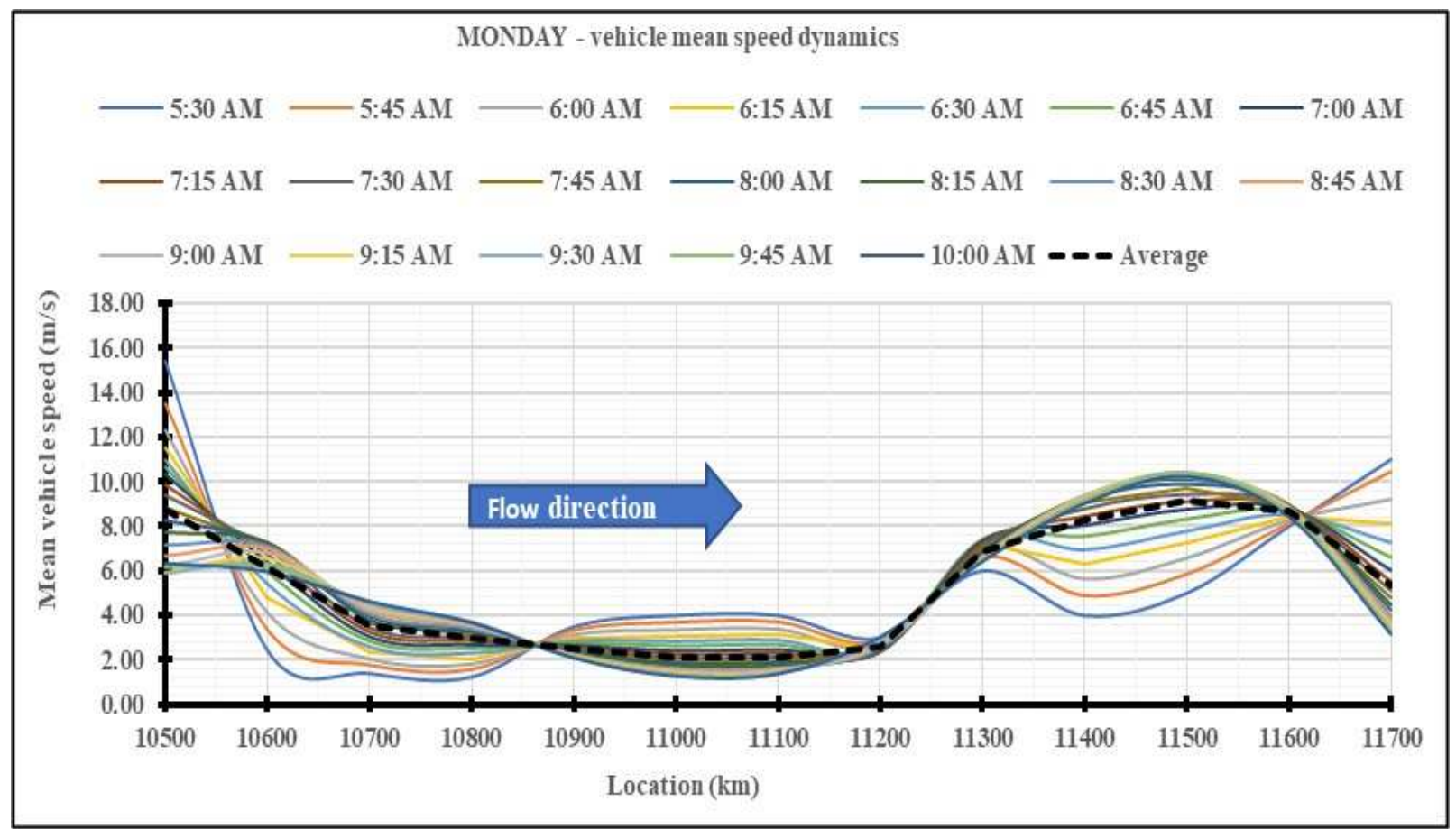

Figure 6a. Monday Vehicle Mean Speed Variations at Tegeta-Nyuki Area

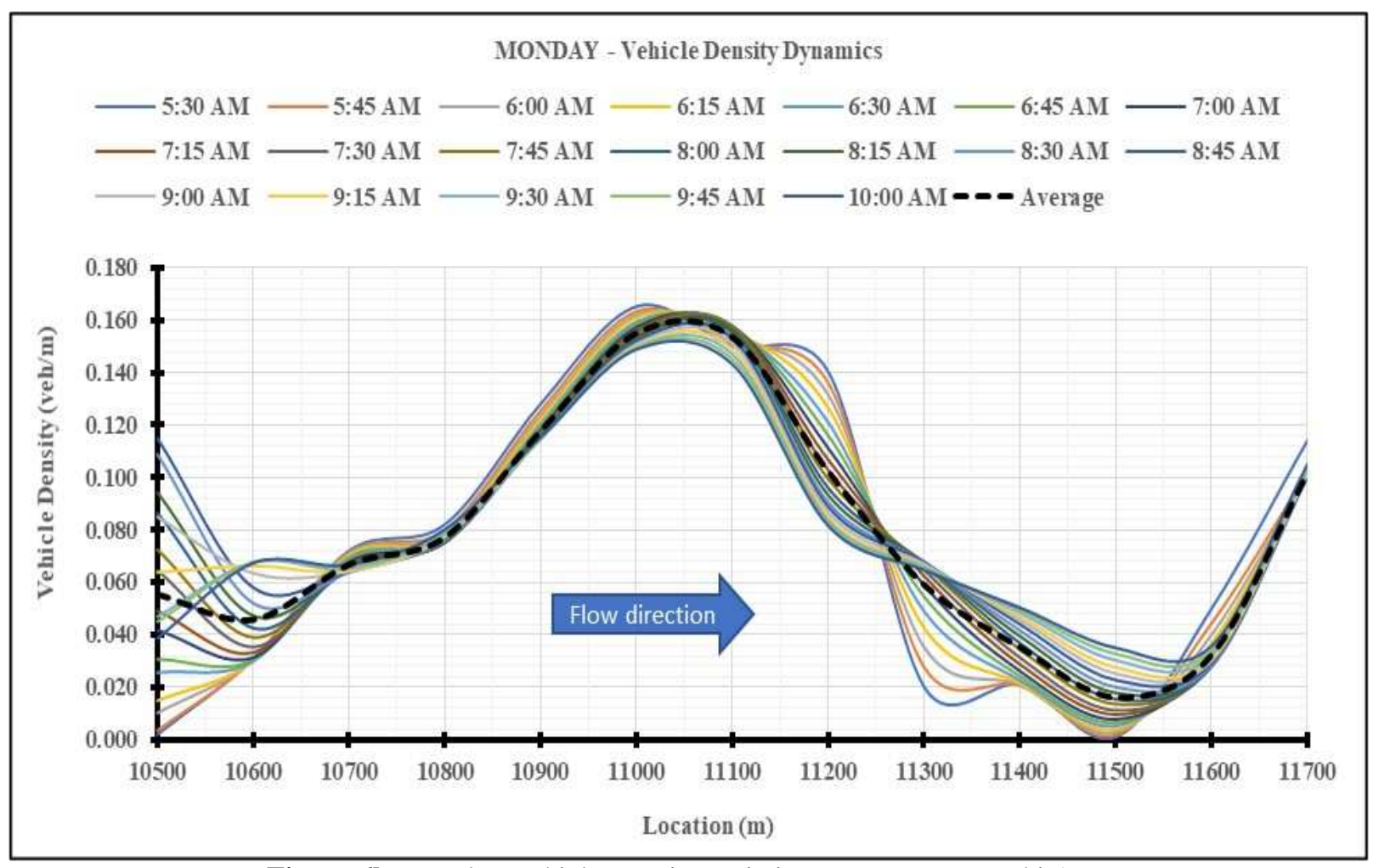

Figure 6b. Monday Vehicle Density variations at atTegeta-Nyuki Area 


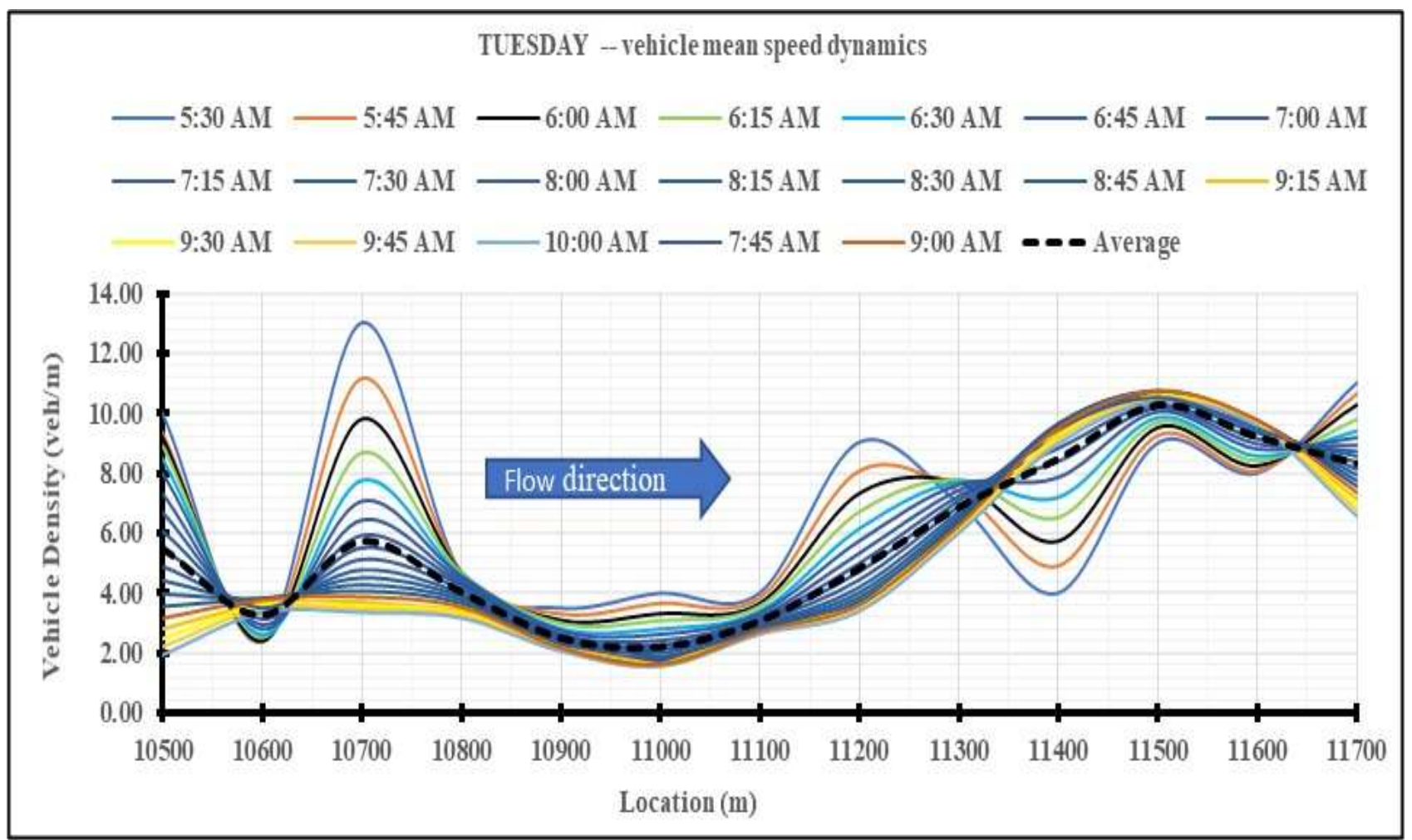

Figure 7a. Tuesday Vehicle Mean Speed variations at Tegeta-Nyuki Area

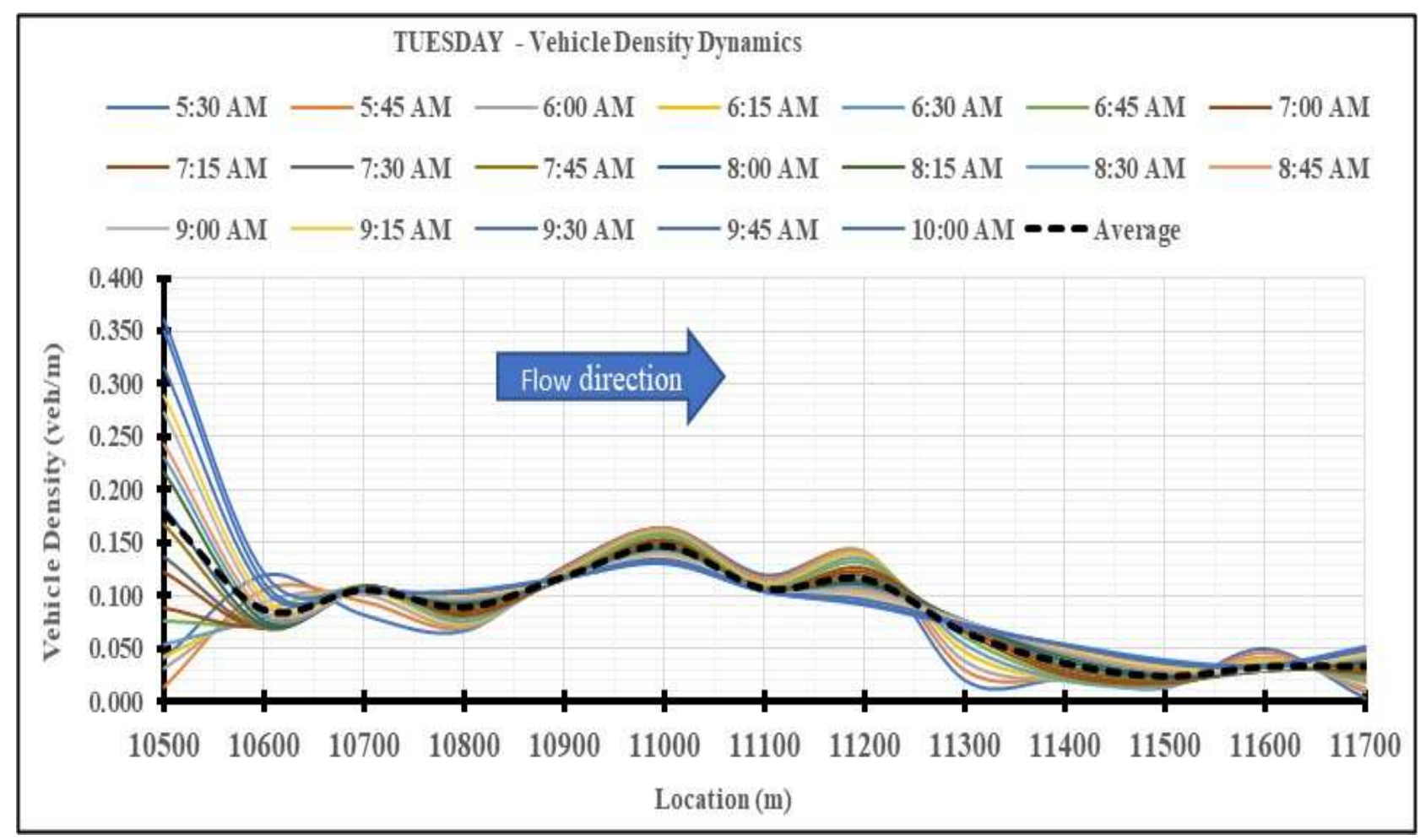

Figure 7b. Tuesday Vehicle Density variations at Tegeta-Nyuki Area 


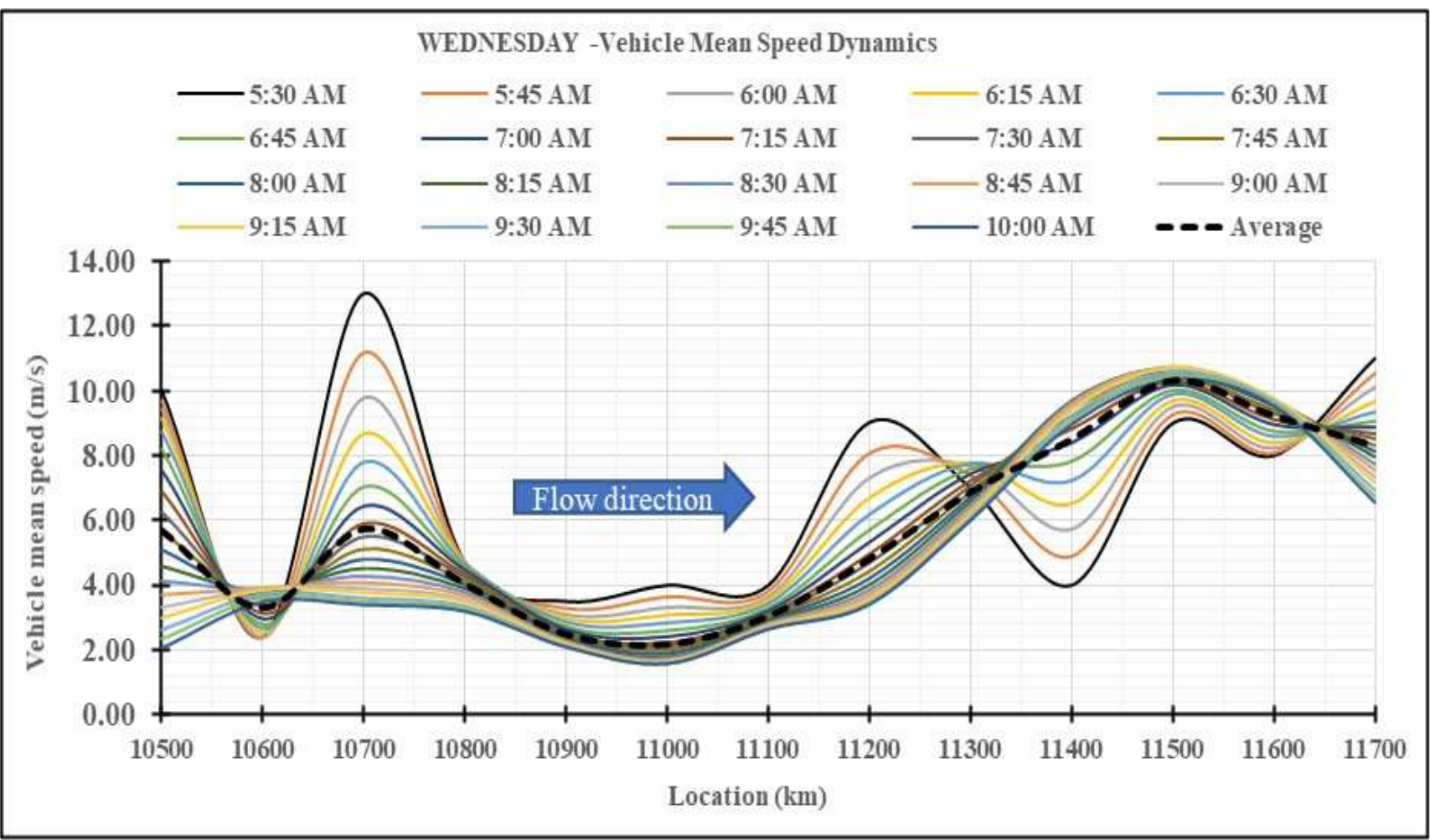

Figure 8a. Wednesday Vehicle Mean Speed variations at Tegeta-Nyuki Area

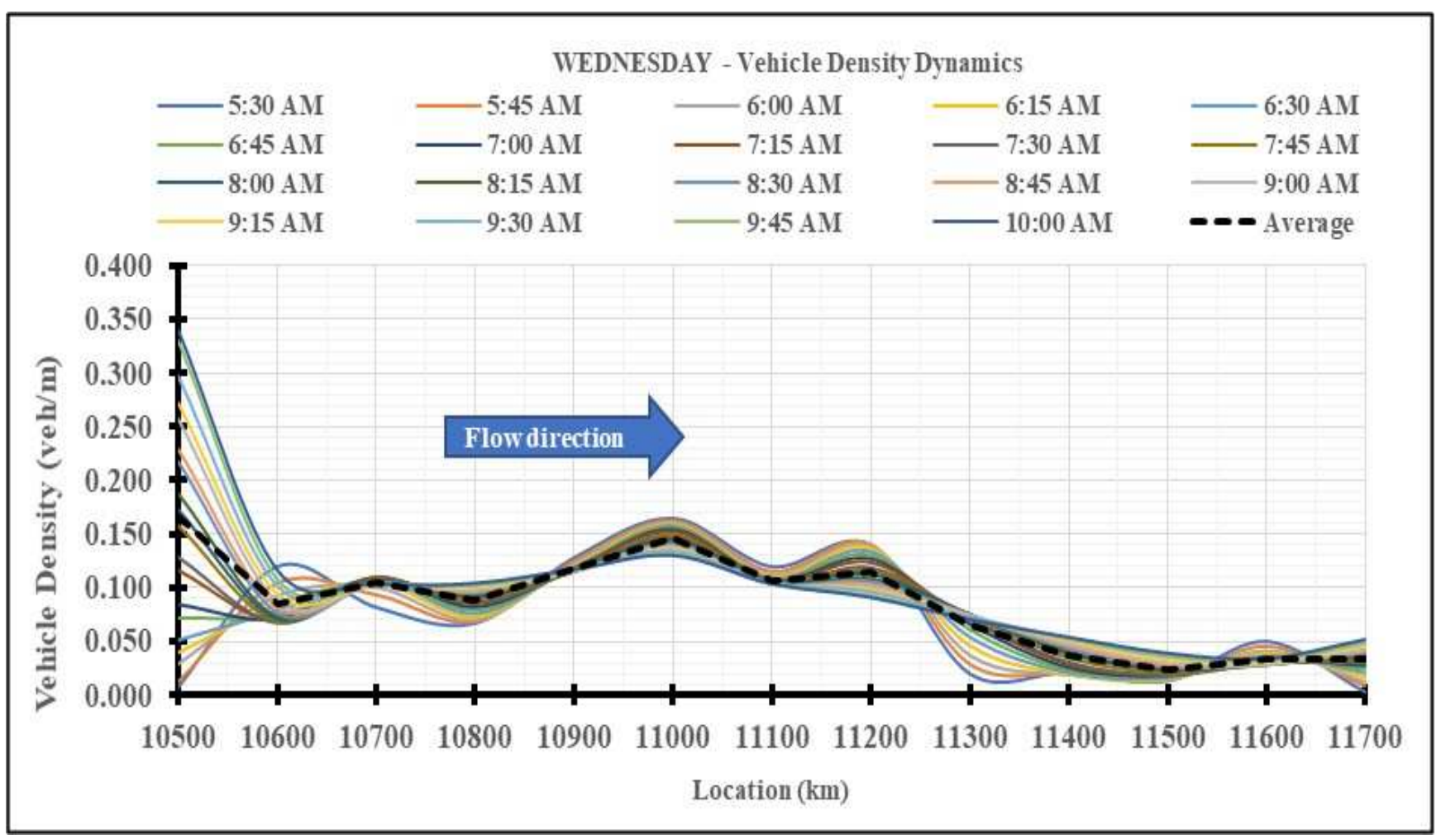

Figure 8b. Wednesday Vehicle Density variations at Tegeta-Nyuki Area 


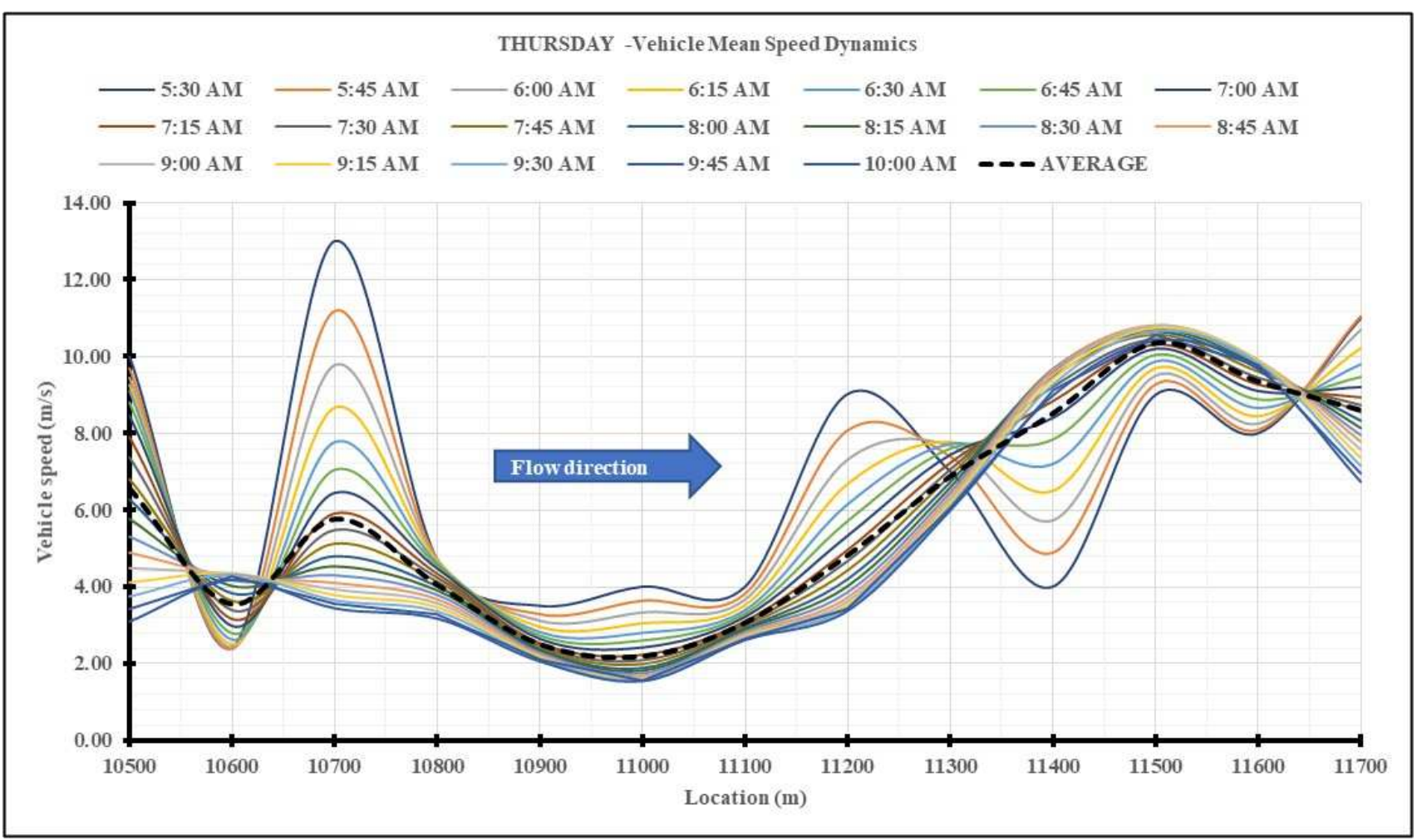

Figure 9a. Thursday Vehicle Mean Speed variations at Tegeta-Nyuki Area

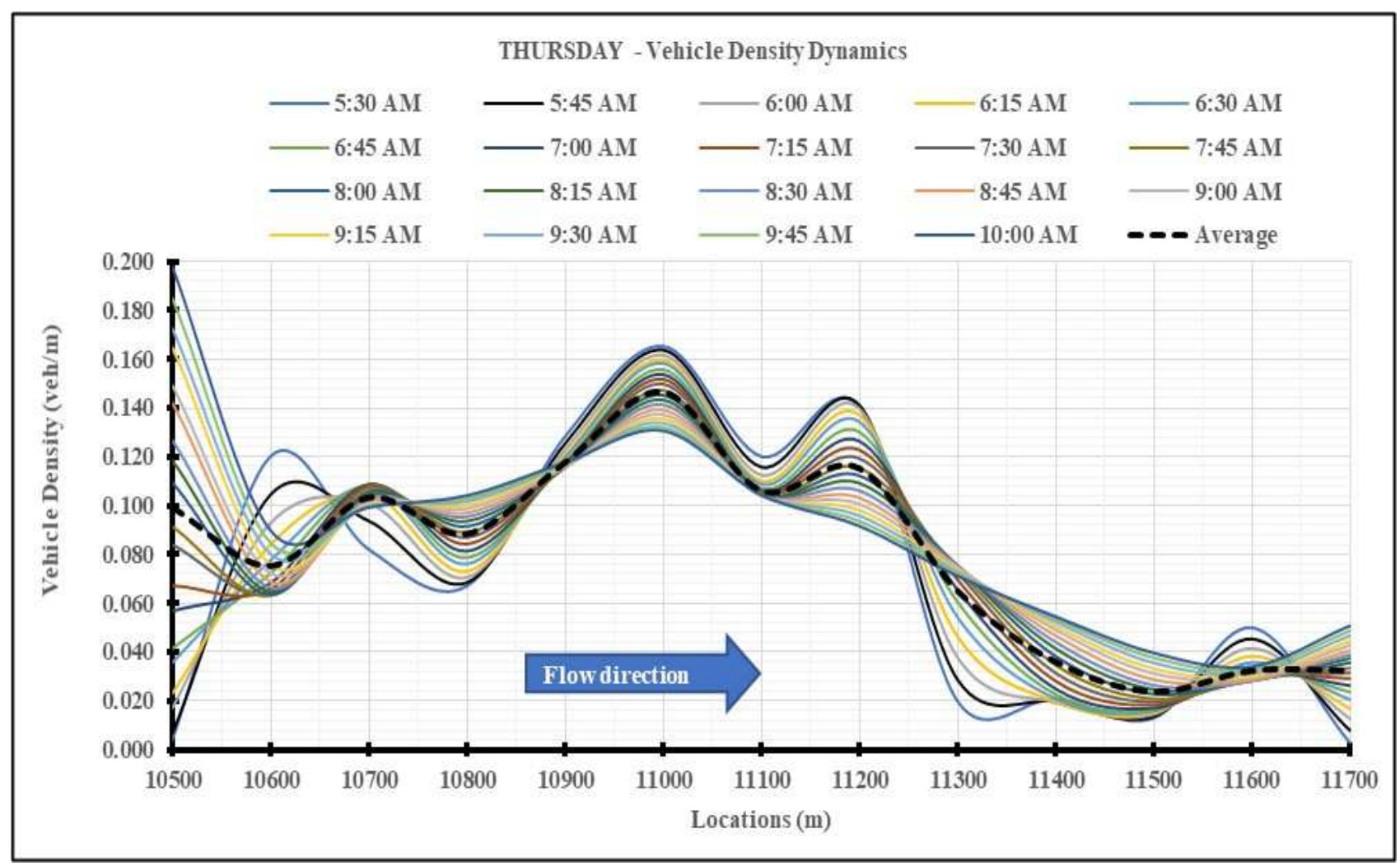

Figure 9b. Vehicle Density variations at Tegeta-Nyuki Area 


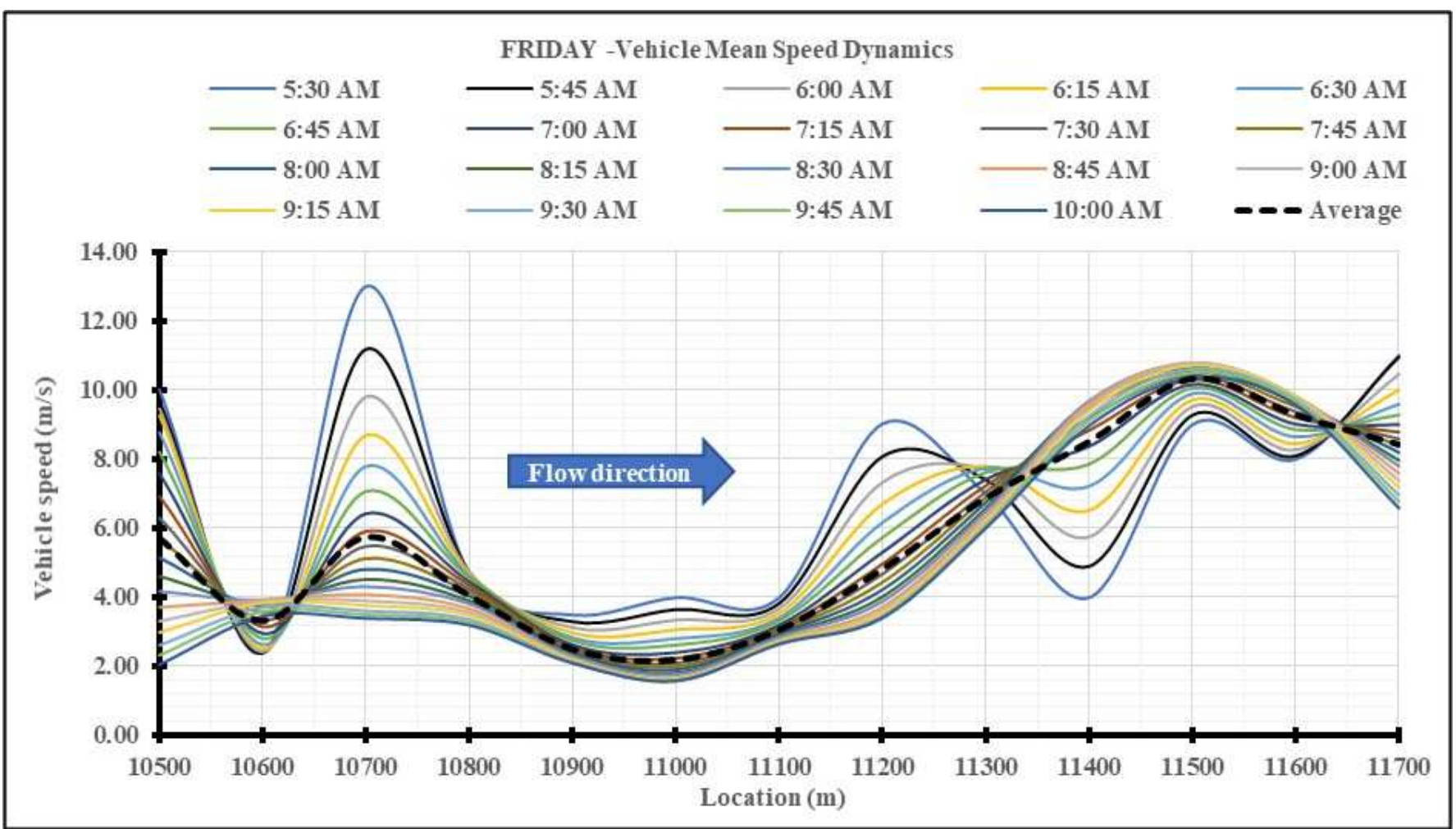

Figure 10a. Friday Vehicle Mean Speed variations at Tegeta-Nyuki Area

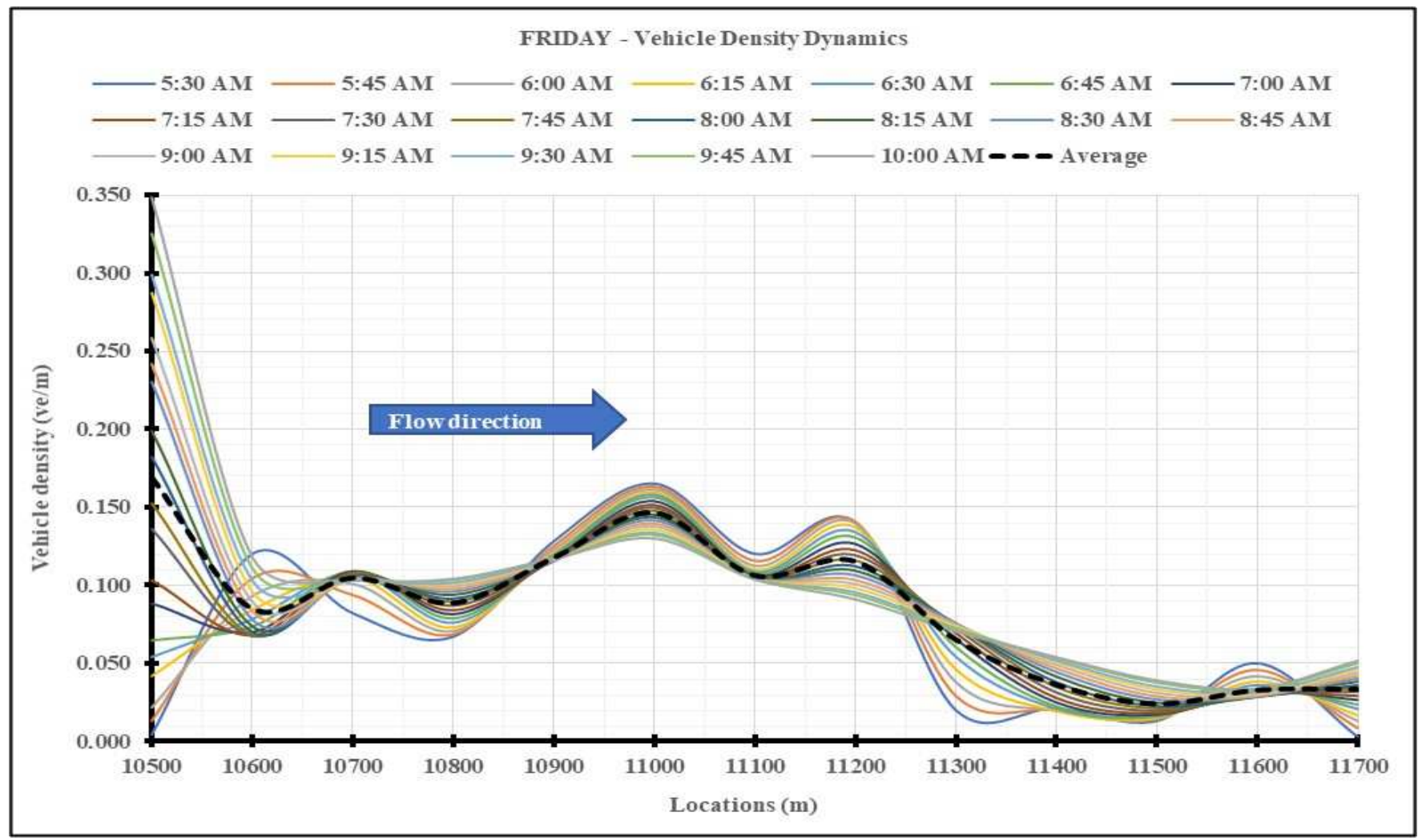

Figure 10 b. Friday Vehicle Density variations at Tegeta-Nyuki Area 


\section{Conclusions}

The effects of the existence of road bottleneck on the roadway were studied applying the modified macroscopic continuum model. The results show that the existence of static bottleneck on the roadway significantly influence both the mean vehicle speed and density by causing decrease of mean speed and increase of vehicle density on approaching the bottleneck. By increasing the vehicle density will lead to huge influences on vehicle flow and thus reducing the roadway performance. From the application point of view, the study of traffic flow in real road network consisting of roads with different road geometries can be conducted applying the proposed model as its fundamental diagrams conform to the one in real traffic situation. Again, the results can be used by the traffic engineers and planners to study the road section for improving the road quality and hence increasing mean vehicle speed and density thus enabling the flow stability of the traffic and running efficiency of the traffic systems. Further study is needed to employ the modified macro model to urban arterial roads that connects to the main roads. This will enable understanding the traffic flow characteristics happening on these roads so as to predict future traffic flow trends to enhance the efficiency of the urban road network systems.

\section{Nomenclature}

CBD Central Business District

CoET College of Engineering and Technology

CTP Critical Traffic Point

DG Density-gradient

LWR Lighthill, Whitham and Richards

SG Speed-gradient

TFE Traffic Friction Effects

\section{Acknowledgement}

The authors would like to acknowledge the financial support given by the National Institute of Transport, Government of Tanzania (the employer of the corresponding author) for carrying out the field data collection.

\section{References}

Ajitha, T., Vanajakshi, L., and Subramanian, S. C. 2015. Real-time traffic density estimation without reliable side road data.

Journal of Computing in Civil Engineering, Vol.29 No. 2, pp. 04014033-1-04014033-8. https://doi.org/10.1061/(ASCE)CP.1943-5487.0000310

Boel, R. and Mihaylova, L. 2006. A compositional stochastic model for real time freeway traffic simulation. Transportation Research Part B: Methodological, Vol. 40 No. 4, pp. 319-334. https://doi.org/10.1016/j.trb.2005.05.001

Daganzo, C. F. 1995. Requiem for second-order fluid approximations of traffic flow. Transportation Research Part B: Methodological, Vol. 29 No. 4, pp277-286. https://doi.org/10.1016/0191-2615(95)00007-Z

Del Castillo, J. M and Benitez, F. G. 1995. On the functional form of the speed-density relationship-I: General theory. Transportation Research Part B: Methodological, Vol. 29 No. 5, pp. 373-389. https://doi.org/10.1016/0191-2615(95)00008-2

Gupta, A. K. 2013. A section approach to a traffic flow model on networks. International Journal of Modern Physics C, Vol. 24 No. 5, pp. 1350018-1 - 1350018-23. https://doi.org/10.1142/S0129183113500186

Gupta, A. K. and Katiyar, V. K. 2006. A new anisotropic continuum model for traffic flow. Physica A: Statistical Mechanics and its Applications, Vol. 368 No. 2, pp551-559. https://doi.org/10.1016/j.physa.2005.12.036

Gupta, A. K. and Katiyar, V. K. 2007. A new multi-class continuum model for traffic flow. Transportmetrica, Vol. 3 No. 1, pp. 73-85. https://doi.org/10.1080/18128600708685665

Gupta, A. K. and Sharma, S. 2010. Nonlinear analysis of traffic jams in an anisotropic continuum model. Chinese Physics B, Vol. 19 No. 11, pp110503-1 - 110503-9.

Gupta, A. K. and Sharma, S. 2012. Analysis of the wave properties of a new two-lane continuum model with the coupling effect. Chinese Physics B, Vol. 21 No. 1, pp. 015201-1 - 015201-15.

Gupta, A. K., and Katiyar, V. K. 2005. Analyses of shock waves and jams in traffic flow. Journal of Physics A: Mathematical and General, Vol. 38, No. 19, pp. 4069-4083.

Hawes, M., Amer, H. M. and Mihaylova, L. 2016. Traffic state estimation via a particle filter with compressive sensing and historical traffic data. In Information Fusion (FUSION), 2016 19th International Conference on. IEEE, 5-8 July 2016, Heidelberg, Germany.

Hou, Z., Xu, J. X. and Yan, J. 2008. An iterative learning approach for density control of freeway traffic flow via ramp metering. Transportation Research Part C: Emerging Technologies, Vol. 16 No. 1, pp71-97. https://doi.org/10.1016/j.trc.2007.06.007 
Jiang, R., Hu, M. B., Jia, B., Wang, R. and Wu, Q. S. 2007. Spatiotemporal congested traffic patterns in macroscopic version of the Kerner-Klenov speed adaptation model. Physics Letters A, Vol. 365 No. 1-2, pp. 6-9.

https://doi.org/10.1016/j.physleta.2006.12.058

Jiang, R., Wu, Q. and Zhu, Z. 2001. A new dynamics model for traffic flow. Chinese Science Bulletin, Vol. 46 No. 4, pp. 345-348. https://doi.org/10.1007/BF03187201

Jiang, R., Wu, Q. S. and Zhu, Z. J. 2002. A new continuum model for traffic flow and numerical tests. Transportation Research Part B: Methodological, Vol. 36 No. 5, pp. 405-419. https://doi.org/10.1016/S0191-2615(01)00010-8

Jin, S., Hou, Z., Chi, R. and Hao, J. 2014. A data-driven control design approach for freeway traffic ramp metering with virtual reference feedback tuning. Mathematical Problems in Engineering, 2014, Article ID 936531, https://doi.org/10.1155/2014/936531

Lattanzio, C., Maurizi, A. and Piccoli, B. 2011. Moving bottlenecks in car traffic flow: a PDEODE coupled model. SIAM Journal on Mathematical Analysis, Vol. 43, No. 1, pp. 50-67. doi: 10.1137/090767224

Leclercq, L., Chiabaut, N. and Trinquier, B. 2014. Macroscopic fundamental diagrams: A cross comparison of estimation methods. Transportation Research Part B: Methodological, Vol. 62, pp. 1-12. https://doi.org/10.1016/j.trb.2014.01.007

Lighthill, M. J., \& Whitham, G. B. 1955. On kinematic waves II. A theory of traffic flow on long crowded roads. Proceedings of the Royal Society of London. Series A. Mathematical and Physical Sciences, Vol. 229, No. 1178, pp. 317-345. https://doi.org/10.1098/rspa.1955.0089

Liu, G., Lyrintzis, A. S. and Michalopoulos, P. G. 1996. Modelling of freeway merging and diverging flow dynamics. Applied Mathematical Modelling, Vol. 20, No. 6, pp. 459-469. https://doi.org/10.1016/0307-904X(95)00165-G

Mahona, J. N. P. D. 2020. Modelling of Traffic Flow Dynamics for Understanding Traffic Congestion in Tanzania: Case of Dar es Salaam City, Doctoral dissertation, Department of Mechanical and Industrial Engineering, College of Engineering and Technology, University of Dar es Salaam, Tanzania.

Mahona, J., Mhilu, C., Kihedu, J. and Bwire, H. 2019. Factors contributing to traffic flow congestion in heterogenous traffic conditions. International Journal for Traffic \& Transport Engineering, Vol. 9 No. 2, pp. 238-254. doi: 10.7708/ijte.2019.9(2).09

Mohan, R. and Ramadurai, G. 2013. Heterogeneous traffic flow modelling using macroscopic continuum model. Procedia-Social and Behavioral Sciences, Vol. 104, pp. 402-411. https://doi.org/10.1016/j.sbspro.2013.11.133

Park E and Oh H. 2015. Automatic Identification of Spatio-temporal Highway Congestion Patterns Using Historic Database. In: Park J., Stojmenovic I., Jeong H., Yi G. (Eds), Computer Science and its Applications. Lecture Notes in Electrical Engineering, Vol 330. Springer, Berlin, Heidelberg

Payne, H. J. 1971. Mathematical Models of Public Systems Simulation Councils Proc.

Richards, P.I., 1956. Shock waves on the highway. Operations Research, Vol. 4 No. 1, pp.42-51.

Strnad, I., Kramar Fijavž, M., and Žura, M. 2016. Numerical optimal control method for shockwaves reduction at stationary bottlenecks. Journal of Advanced Transportation, Vol. 50 No. 5, 841- 856. https://doi.org/10.1002/atr.1378

Tang, C. F., Jiang, R. and Wu, Q. S. 2007. Phase diagram of speed gradient model with an on-ramp. Physica A: Statistical Mechanics and its Applications, Vol. 377 No. 2, pp. 641-650. https://doi.org/10.1016/j.physa.2006.11.058

Tang, T. Q., Li, Y. and Huang, H. J. 2009. The effects of bus stop on traffic flow. International Journal of Modern Physics C, Vol. 20 No. 6, pp. 941-952. https://doi.org/10.1142/S0129183109014096

Tang, T. Q., Shi, W. F., Yang, X. B., Wang, Y. P., and Lu, G. Q. 2013. A macro traffic flow model accounting for road capacity and reliability analysis. Physica A: Statistical Mechanics and its Applications, Vol. 392 No. 24, pp. 6300-6306. https://doi.org/10.1016/j.physa.2013.07.035

Tie-Qiao, T., Peng, L., Yong-Hong, W. and Hai-Jun, H. 2012. A macro model for traffic flow with consideration of static bottleneck. Communications in Theoretical Physics, Vol. 58 No 2, pp. 300-306.

\section{Biographical notes}

John N. P. Mahona is working at Department of Transport Engineering and Technology, National Institute of Transport, Dar es Salaam. Currently, he is doing a $\mathrm{Ph} . \mathrm{D}$. in Engineering at the University of Dar Es Salaam, Tanzania.

Cuthbert F. Mhilu is a Professor in the Department of Industrial and Mechanical Engineering, University of Dar Es Salaam, Tanzania

Hannibal Bwire is a Senior Lecturer in the Department of Transportation and Geotechnical Engineering, University of Dar Es Salaam, Tanzania

Joseph Kihedu is a Senior Lecturer in the Department of Industrial and Mechanical Engineering, University of Dar Es Salaam, Tanzania 